\title{
Becoming Famous Without Being Recognized: Unconscious Influences of Memory Produced by Dividing Attention
}

\author{
Larry L. Jacoby and Vera Woloshyn \\ McMaster University \\ Hamilton, Ontario, Canada \\ Colleen Kelley \\ Williams College
}

\begin{abstract}
The familiarity of names produced by their prior presentation can be misinterpreted as fame. We used this false fame effect to separately study the effects of divided attention on familiarity versus conscious recollection. In a first experiment, famous and nonfamous names were presented to be read under conditions of full vs. divided attention. Divided attention greatly reduced later recognition memory performance but had no effect on gains in familiarity as measured by fame judgments. In later experiments, we placed recognition memory and familiarity in opposition by presenting only nonfamous names to be read in the first phase. Recognizing a name as earlier read on the later fame test allowed Ss to be certain that it was nonfamous. Divided attention at study or during the fame test reduced list recognition performance but had no effect on familiarity. We conclude that conscious recollection is an attention-demanding act that is separate from assessing familiarity.
\end{abstract}

Folk wisdom suggests that we benefit from experience by consciously remembering those experiences and applying the knowledge gained from them to the current situation. In contrast, research shows that many effects of prior experience on later performance can occur independently of the ability to consciously recollect the experience (see Richardson-Klavehn \& Bjork, 1988, for a review). In this article, we provide further evidence that the past can be used to influence present performance without the intervention of conscious recollection. We show that divided attention, in comparison with full attention, can radically reduce a person's ability to recognize an item as previously presented while leaving intact the effects of that prior presentation on judgment. Furthermore, this potential for unconscious influence of the past leads to a role for conscious recollection that is directly counter to that advanced by folk wisdom. Rather than being a prerequisite for producing effects of the past, conscious recollection can be a means of escaping misleading effects of the past.

The task that we used required subjects to judge whether a name was famous. In the first phase of each experiment, people read a list of names. Then those old names were mixed with new famous and new nonfamous names in a test of fame judgments. On the basis of earlier research (Jacoby, Kelley, Brown, \& Jasechko, 1989; Neely \& Payne, 1983), we expected

This research was supported by a grant to Larry L. Jacoby from the Canadian National Science and Engineering Research Council.

We thank Gus Craik, Marcia Johnson, and Ronald Kinchla for their comments on an earlier version of this article. We also thank Ian Begg for his suggestions concerning the analyses of data and Ann Hollingshead for collecting and analyzing the data.

Correspondence concerning this article should be addressed to Larry L. Jacoby, Department of Psychology, McMaster University, Hamilton, Ontario L8S 4K1, Canada. that the familiarity of a name produced by its being read in the first phase would be mistaken for the familiarity that characterizes a famous name; that is, reading either a famous name or a nonfamous name in the first part of the experiment would produce a higher probability of calling the name "famous" on the later test. We expected that divided attention would reduce people's ability to recognize a name as previously read but would have no effect on gains in the familiarity of the name produced by its prior reading.

When one is unable to consciously recollect having read a name, any remaining effect of reading it on its familiarity can be considered an unconscious influence of memory. We have found it useful to think about such effects of the past in terms of Polanyi's (1958) distinction between tool and object (Jacoby \& Kelley, 1987). Memory can be used unconsciously as a tool to accomplish a present task, or it can be made the object of reflection for conscious remembering. That framework predicts a difference in focus of attention and processing requirements for conscious recollection, in comparison with unconscious uses of memory. Conscious recollection is seen as involving an act that is separate from the use of memory as a tool to help accomplish some present task.

The notion of conscious recollection as a separate act highlights the possibility that consciousness sometimes serves to oppose unconscious influences of the past that would otherwise prevail. For example, we can use conscious recollection to avoid repeating our stories to the same audience or to avoid unconscious plagiarism. In these cases, recognition in the form of conscious recollection is not a prerequisite for effects of the past, but instead it serves as a means of avoiding undesirable effects of the past. The opposition of conscious and unconscious influences of memory can also be used as a methodological tool to provide a clear separation of the two in performance. 
In the second and third experiments, we placed conscious recollection in opposition to effects of reading a name on the judgment of its fame. We arranged the situation so that recognition of a name as previously read allowed subjects to be certain that it was nonfamous. Only nonfamous names were presented in the first phase of the experiment, and subjects were told that this was the case. Reading a nonfamous name has the unconscious influence of increasing the familiarity of that name and makes it more likely that the name will later mistakenly be called "famous." Conscious recollection of the name as read in the earlier list opposes this unconscious influence and allows one to be certain that the name is nonfamous. Given this arrangement, any increase in the probability of mistakenly calling a nonfamous name "famous" must result from an unconscious influence of the past because conscious recollection of the name as previously read in the list of nonfamous names would dictate an opposite response. Thus placing the two in opposition allows one to separate the effects of conscious recollection from unconscious influences of the past.

There is some evidence that manipulations of attention have a larger effect on conscious recollection than on uses of memory that do not require awareness of the past. When sufficient care is taken to ensure that items are truly unattended, little or no evidence of memory is found on a recognition memory test or a recall test (Fisk \& Schneider, 1984; Moray, 1959), which leads to the claim that attention is necessary for memory. However, Eich (1984) found evidence of memory after divided attention by using a test that did not require conscious recollection. Homophones were presented to the unattended channel in a dichotic-listening task, accompanied by a word that biased the homophone to its less common interpretation (e.g., taxi-fare). Although divided attention reduced recognition of the homophones to chance, memory for their prior presentation was indirectly revealed by biased spelling of the homophones on a later test. Similarly, Koriat and Feuerstein (1976) showed differential effects of an attention manipulation on conscious recollection, in comparison with memory, as measured by an increased probability of producing earlier presented words on a free-association test. Grand and Segal (1966) used a similar indirect measure of memory and also showed differential effects of a manipulation of attention on that measure, in comparison with recall.

We expected parallels between the effects of divided attention on normal subjects' memory performance and amnesics' performance on memory tasks (e.g., Craik, 1982). Amnesics do show some ability to recognize items, but it appears to be based simply on the familiarity of items, rather than on any ability to consciously recollect a particular prior occurrence. Huppert and Piercy (1978) found that their Korsakoff patients could make recency judgments at an above-chance level, but they tended to judge items presented frequently as having been presented recently and vice versa. In other words, amnesics based both types of judgments on the memory strength or familiarity of the item and so were unable to discriminate between frequency and recency. In contrast, subjects with normal memories could use their recollection of particular occurrences of an item to disentangie the effects of recency and frequency of presentation. Similarly, divided attention at study may prevent later recollection of an event but may not prevent increments in the general familiarity of an item. That familiarity could then be used as a basis for a variety of judgments, such as recency, frequency, or general familiarity of an item.

The goal in our first experiment was to further document that divided attention, in comparison with full attention, during study can produce a large decrement in list-recognition memory performance while having little or no effect on an unconscious use of memory as a tool. Famous names and nonfamous names were presented to be read aloud under conditions of divided or full attention. Gains in familiarity of names were tracked by changes in performance on a later fame-judgment test, and list-recognition memory was assessed with a standard recognition test. We expected a dissociation between gains in familiarity and list-recognition performance, such that previously read names would be judged as famous but not recognized after divided attention. However, familiarity can serve as one basis for calling an item "old" on a test of recognition memory (e.g., Jacoby \& Dallas, 1981; Mandler, 1980). Consequently, we did not expect list-recognition performance in the divided-attention condition to be near chance because dividing attention was not expected to disrupt gains in familiarity. Conscious recollection or the retrieval of study context serves as an alternative basis for recognition memory judgments and is the basis for list recognition that we expected to be influenced by the dividing of attention during study.

In later experiments, we placed conscious recollection in opposition to gains in familiarity by presenting only nonfamous names in the first phase of the experiments. We also investigated whether conscious recollection requires an attention-demanding act that is separate from other uses of the past by dividing attention during the fame test (Experiment 3 ). When attention is divided during study (Experiment 2) or during the test (Experiment 3), old nonfamous names might continue to gain false fame, although subjects are told that all old names are nonfamous. Dividing attention during study or during the test may prevent the processing necessary to consciously recollect a name as previously read while leaving intact the effects of reading a name on its familiarity.

\section{General Method}

Throughout the three experiments, we used one basic paradigm. Variations in the general method are indicated as each experiment is described.

\section{Subjects}

The subjects were volunteers from an introductory psychology course at McMaster University who served in an experiment for course credit. Subjects were randomly assigned to conditions and were tested individually.

\section{Tasks and Materials}

In the first phase of each experiment, names were presented to be read aloud under conditions of either full or divided attention. In the divided-attention condition, subjects read the names while listening 
to a very long continuous string of numbers with target sequences embedded in the string. Subjects were to search for runs of three oddnumbered digits. Names read in the first phase were mixed with new famous and new nonfamous names for a test of list recognition or fame judgments. For the list-recognition test, subjects judged whether a name had been read in the first phase of the experiment. For the fame-judgment test, subjects judged whether a name was a famous one. List recognition indicated a conscious use of memory. An increase in the probability that a name would be judged famous because of its prior presentation potentially indicated an unconscious use of memory.

The listening task used in the divided-attention conditions was one previously used by Craik (1982). Forty-three sequences of 3 odd numbers occurred within a list of 224 random numbers. The restrictions that we used to construct the list were that a minimum of 1 and a maximum of 8 numbers must occur between the end of one and the beginning of the next target sequence. Also, not more than 3 even numbers could occur in sequence. The number of target sequences presented was determined by the length of the study list or, in Experiment 3, the length of the test list.

A pool of famous and nonfamous names, including first and last names, was used as materials for the experiments. We attempted to find famous names of the sort that the majority of people could recognize as famous but that were not so famous that most subjects could specify the achievement that led to fame. This criterion for the choice of famous names was meant to make it likely that people would base their judgments of fame on the familiarity of the name rather than on their ability to recall what the named person had done to become famous. Data from other experiments done in our lab were used to select famous names identified as famous by $60 \%-70 \%$ of students from the same undergraduate population as tested here. Nonfamous names were matched with the famous names according to the following characteristics: length of first and last name, sex indicated by the first name, and the nationality of origin of the last name. Examples of nonfamous names are Scbastian Weisdorf, Valerie Marsh, and Adrian Marr. Examples of famous names are Satchel Paige, Minnie Pearl, and Christopher Wren.

The presentation order of names for both study and test lists was random with the restriction that not more than three names of one type (famous vs. nonfamous or old vs. new) could be presented before one name of each of the other types. Two study lists were prepared in such a way that names that were old for the fame judgment test when one study list was used were new when the other study list was used and vice versa. Two random presentation orders of items in each study list were used to produce four combinations of study list and random order. Each combination was used equally often.

\section{Procedure}

Names were presented by means of an Apple computer interfaced with a Zenith monitor. In the first phase of each experiment, the names appeared for $2 \mathrm{~s}$; the initial letter of each first and last name was capitalized. There was a 1-s blank interval after the presentation of each name. For the listening task used in the divided-attention condition, digits were presented in a continuous stream at a12-s rate per digit. The auditory presentation of digits slightly preceded the visual presentation of names.

Subjects were instructed to read presented names aloud during the first phase of each experiment. Those in a full-attention condition were told that we were interested in their speed and accuracy of pronouncing names and that their pronunciation of names was being recorded. Although a microphone was placed on top of the monitor to make the instructions more credible, neither pronunciations nor latencies were actually recorded. Subjects in a divided-attention con- dition were told that the task of reading names aloud was meant only to interfere with the more important task of listening for runs of three odd-numbered digits. They were instructed to devote as little attention as possible to their pronunciation of the names and to concentrate on the listening task, pressing a key whenever they heard a target in the listening task. Accuracy of performance on the listening task was recorded.

Before the test of fame judgments, subjects were informed that the famous names were not as extremely famous as Wayne Gretzky or Pierre Trudeau. They were also told that they would not be asked to describe what a named person had done to become famous. These instructions encouraged subjects to use familiarity as a basis for their fame judgments. Subjects made their fame judgments by pressing a key on the right for "famous" and a key on the left for "nonfamous." After their decision, the message "Press center key when ready" appeared on the screen. Pressing the center key resulted in the presentation of another name for a judgment of its fame. This sequence of events was repeated until all of the names in a list had been tested. Each judgment and its latency were recorded by the computer.

For the test of recognition memory, old names and new names were intermixed and printed in columns on a sheet of paper. Subjects were instructed to circle names that they had read in the first phase of the experiment.

\section{Analyses}

Decision-time analyses were for correct judgments only (judgments of famous names as famous and nonfamous names as nonfamous). Times for errors were also examined but are not reported because they were based on fewer observations and were not obtainable for all subjects. An examination of the error times did not reveal any effects that compromise conclusions drawn on the basis of times of correct responses. A log transformation of each subject's decision times was used to lessen the impact of extreme scores on the means. The significance level for all tests was set at $p<.05$.

\section{Experiment 1}

\section{Method}

Subjects and design. The subjects were 64 students enrolled in an introductory psychology course; 32 subjects were randomly assigned to each of two (full vs. divided) attention conditions. For each subject, the fame-judgment test was followed by the list-recognition memory test. Within subjects, prior presentation of names (old vs. new) was factorially combined with fame of the names (famous vs. nonfamous) for each of the two types of test.

Materials and procedure. A list of 65 names was presented to be read in the first phase of the experiment. The first 5 names in the list included 3 famous and 2 nonfamous names that served only as fillers (not tested later). The remaining 60 names included 30 famous and 30 nonfamous names. Of those, 20 famous and 20 nonfamous names were mixed with 20 new famous and 20 new nonfamous names for the fame-judgment test. The remaining 10 names of each type were mixed with 10 new famous and 10 new nonfamous names for the recognition memory test.

Before the fame-judgment test, subjects were informed that half of the names that they read in the first phase were famous and half were nonfamous, and so recognition of a name as previously read provided no information about its fame. The procedure used in the famejudgment test was as described in the General Method section. After the fame-judgment test, subjects were given the list-recognition mem- 
ory test. Names were presented on a sheet of paper, and subjects were told to circle names that they had read in the first phase of the experiment.

\section{Results and Discussion}

Subjects in the divided-attention condition missed an average of 5.3 of 27 targets in the listening task. The pronunciation of names was generally accurate even when attention was divided. An average of 2.41 of the names presented in the first phase were mispronounced, not pronounced, or stumbled over when attention was divided.

Famous names were more likely to be judged famous (.59) than were nonfamous names $(.19), F(1,62)=282, M S_{c}=$ 0.035 (see Table 1). Names that had been read in the first phase of the experiment were more likely to be judged famous (.46) than were names that were new at the time of test $(.32)$, $F(1,62)=159.78, M S_{\mathrm{e}}=0.007$. Although reading a name earlier did produce a bias toward calling the name "famous," the discriminability between famous and nonfamous names was not influenced by previously reading the names; that is, the interaction between prior presentation and the fame of names did not approach significance. An analysis of judgment times showed that old famous names were judged famous more rapidly than were new famous names $(1,167$ vs. 1,270 $\mathrm{ms}), F(1,62)=12.75, M S_{c}=26,921$. There was also a tendency for old nonfamous names to be rejected more slowly than were new nonfamous names (1,456 vs. $1,417 \mathrm{~ms}), F(1$, $62)=3.62, M S_{e}=13,738, p<.06$.

Of most importance for our purposes, dividing attention did not affect the gain in familiarity of names produced by their having been read earlier. Neither the main effect of attention condition nor any interaction involving the manipulation of attention approached significance in any of the analyses of fame judgments. This lack of an effect of the manipulation of attention on fame judgments is in marked contrast with the large effect of attention on list recognition memory performance. An analysis of the probabilities of calling a name "old" (see Table 1) showed that old names were more likely to be called "old" than were new names and that the effect of prior presentation interacted with the manipulation of attention. The probability of a hit was higher and the probability of a false alarm was lower in the fullattention condition (.65 and .04$)$ than in the divided-attention condition (.43 and .13). There were also a significant main

Table 1

Fame and Recognition Judgments: Experiment 1

\begin{tabular}{cccccc}
\hline & \multicolumn{2}{c}{ New } & & \multicolumn{2}{c}{ Old } \\
\cline { 6 - 7 } \cline { 5 - 6 } Condition & F & NF & & F & NF \\
\hline Fame & & & & \\
$\quad$ Full attention & .49 & .13 & & .66 & .25 \\
$\quad$ Divided attention & .53 & .14 & & .66 & .25 \\
Recognition & & & & \\
$\quad$ Full attention & .04 & .05 & & .70 & .60 \\
$\quad$ Divided attention & .13 & .13 & & .47 & .39 \\
\hline
\end{tabular}

Note. $\mathrm{F}=$ famous names; $\mathrm{NF}=$ nonfamous names. The numbers are the probabilities of responding "famous" for fame judgments and the probabilities of responding "old" for recognition judgments. effect of fame, $F(1,62)=5.75, M S_{c}=0.021$, and a significant interaction between fame and prior presentation, $F(1,62)=$ $11.13, M S_{e}=0.014$. Old famous names were more likely to be called "old" (.59) than were old nonfamous names (.50), whereas there was no difference in the probabilities of mistakenly calling new famous names (.09) and new nonfamous names (.09) "old." The Attention $\times$ Prior Presentation $\times$ Fame interaction was not significant $(F<1)$; that is, old famous names did not hold a significantly larger advantage over old nonfamous names in the full-attention condition than in the divided-attention condition.

The data are consistent with the claim that dividing attention reduces list-recognition memory performance, whereas it has no effect on gains in familiarity. The effects of reading a name on a later judgment of its fame largely replicate results reported by Neely and Payne (1983). Those effects remain unchanged when attention is divided while one reads names, even though divided attention, in comparison with full attention, has a large effect on list-recognition performance. This dissociation between effects on familiarity and recognition is similar to dissociations observed in the memory performance of amnesics (e.g., Huppert \& Piercy, 1978) and is also similar to differential effects of attention observed by others (Eich, 1984; Koriat \& Feuerstein, 1976).

One interpretation of the dissociation between familiarity and item recognition that we observed would be that familiarity relies on the priming of preexisting units (Morton, 1969), whereas conscious recollection relies on a different mechanism. However, the priming interpretation is implausible, given that the gain in fame due to reading a name was as large for nonfamous names (with no preexisting representation) as for famous names. Elsewhere (Jacoby \& Brooks, 1984; Jacoby \& Kelley, 1987) we have discussed other reasons for rejecting priming accounts of unconscious influences of memory. Effects on familiarity seem better viewed as resulting from adding new information to memory rather than from priming preexisting knowledge.

\section{Experiment 2}

To preclude the possibility that our measure of familiarity actually reflects some instances of conscious recollection, we placed gains in familiarity and conscious recollection in opposition to one another to further separate the two processes. In our second experiment, all names presented in the first phase were nonfamous; thus conscious recollection of a name as old allowed subjects to be certain that the name was nonfamous. Familiarity without conscious recollection would yield the opposite response, calling a name "famous." Attention was either full or divided during list presentation.

Subjects in the divided-attention condition were not necessarily helpless victims of the false fame effect. If they suspected that their fame judgments were influenced by prior presentation of nonfamous names but realized that their listrecognition memory was poor, they might react by being less willing than subjects in the full-attention condition to call any name "famous." Such a strategy would reduce the probability of judging both old and new names as famous, but it would eliminate confusion between prior presentation and fame only 
if all the new famous names were more familiar than the old nonfamous names. To assess the possibility of such a change in criterion across attention conditions, we did a signaldetection analysis, using the probability of calling a famous name "famous" as a measure of hits and the probability of calling a new nonfamous name "famous" as a measure of false alarms. If divided attention changes subjects' criterion, we would see a change in the probability of calling both famous and nonfamous names "famous" without a corresponding change in discrimination between the two types of names.

\section{Method}

Subjects and design. The subjects were 40 undergraduates enrolled in an introductory psychology course; 20 subjects were randomly assigned to each of two attention conditions (full vs. divided). Names on the fame-judgment test were famous, nonfamous and earlier read (old nonfamous), or nonfamous and not earlier read (new nonfamous).

Materials and procedure. In the first phase of the experiment, subjects read a list of 40 nonfamous names aloud under conditions of either full or divided attention. The listening task used in the divided-attention condition was the same as in the first experiment except that digits were presented at a 2 -s rate. The first 5 and the last 5 names read in the first phase of the experiment were mixed with 10 new nonfamous names and were later presented for a test of recognition memory. The remaining 30 old nonfamous names were mixed with 30 new nonfamous names and 60 new famous names and presented for fame judgments. Multiple formats of the list read in the first phase were constructed in such a way that across formats the names appeared equally often as old nonfamous names or as new nonfamous names in the fame-judgment test. The old nonfamous names used in the recognition memory test remained constant across formats and so were not balanced with those used as new nonfamous names on that test.

After reading names in the first phase of the experiment, subjects were informed that all of the names that they had read were nonfamous ones and that those names would be presented with new famous and new nonfamous names for judgments of fame. The procedure for the fame judgment test was as described in the General Method section. After the fame-judgment test, the test of list recognition was given. Names were presented on a sheet of paper, and subjects were instructed to circle names that they had read in the first phase of the experiment. Because of experimenter error, 20 subjects in each of the attention conditions completed the test of fame judgments, but only the last 15 subjects tested in each condition were given the test of recognition memory.

\section{Results and Discussion}

An average of 1.5 of 12 targets were missed in the listening task used in the divided-attention condition. Pronunciation of names was not recorded.

We measured the probability of calling a name "famous" (see Table 2) for each of the three types of name (famous, old nonfamous, and new nonfamous) and each of the two attention conditions (full and divided). We first compared performances on the famous and the new nonfamous names to test for any differences between the two attention conditions in discriminability or criterion used for fame judgments. That analysis revealed that famous names were more likely to be judged famous than were new nonfamous names, $F(1,38)=$ 86.70, $M S_{\mathrm{e}}=2.29$. Also, subjects in the divided-attention condition were less willing to judge a name to be famous, regardless of its true status, than were subjects in the fullattention condition, $F(1,38)=10.59, M S_{c}=3.28$. We performed a signal-detection analysis by using fame judgments to obtain estimates of $d^{\prime}$ (discriminability) and of $\beta$ (criterion for judging a name as famous) for each subject and then entering those estimates into an analysis of variance. That analysis revealed that $d^{\prime}$ did not differ between the two attention conditions, $F(1,38)<1$. However, $\beta$ was higher in the divided-attention condition (2.48) than in the full-attention condition $(1.46), F(1,38)=5.12, M S_{\mathrm{e}}=2.037$.

The use of a higher criterion by subjects in the dividedattention condition than in the full-attention condition was probably meant to protect themselves against being misled by familiarity. Unlike subjects in the full-attention condition, subjects in the divided-attention condition could not rely on list recognition to avoid the misleading effects of familiarity. As will be shown, list-recognition performance was very poor in the divided-attention condition. The lack of a difference in $d^{\prime}$ provides evidence that there was no qualitative difference between the two conditions in the basis used for fame judgments.

Most important were the effects of the attention manipulation on the probabilities of mistakenly judging old and new nonfamous names "famous." An analysis of those data revealed an interaction between attention condition and type of nonfamous name, $F(1,38)=22.21, M S_{\mathrm{e}}=1.00$. As predicted, in the full-attention condition, old nonfamous names were less likely to be judged famous than were new nonfamous names, whereas the opposite was true in the divided-attention condition. An analysis of times for correctly rejecting nonfamous names produced results that were consistent with those from the analysis of probabilities. That analysis revealed a main effect of type of nonfamous name, $F(1,38)=5.93, M S_{\mathrm{e}}=16,989$, and a significant interaction between type of nonfamous name and attention condition, $F(1,38)=12.45, M S_{\mathrm{c}}=16,989$. In the full-attention condition, old nonfamous names were rejected more rapidly than were new nonfamous names $(1,256 \mathrm{vs} .1,430 \mathrm{~ms})$, whereas in the divided-attention condition, old nonfamous names required approximately the same amount of time to be rejected as did new nonfamous names (1,203 vs. $1,171 \mathrm{~ms})$. An

Table 2

Fame and Recognition Judgments: Experiment 2

\begin{tabular}{cccc} 
& & \multicolumn{2}{c}{$\begin{array}{c}\text { Nonfamous } \\
\text { name }\end{array}$} \\
\cline { 3 - 4 } Condition & $\begin{array}{c}\text { Famous name: } \\
\text { New }\end{array}$ & New & Old \\
\hline Fame & .62 & .31 & .19 \\
Full attention & .49 & .17 & .27 \\
$\begin{array}{c}\text { Divided attention } \\
\text { Recognition } \\
\text { Full attention }\end{array}$ & - & .00 & .63 \\
Divided attention & - & .11 & .30 \\
\hline
\end{tabular}

Note. The numbers are the probabilities of responding "famous" for fame judgments and the probabilities of responding "old" for recognition judgments. 
analysis of the speed of correctly accepting famous names as being famous failed to reveal a significant difference between the two attention conditions.

According to the recognition memory data (see Table 2), divided attention, in comparison with full attention, to the reading of names radically reduced list-recognition performance. The probability of calling a name "old" was higher in the full-attention than in the divided-attention condition, $F(1$, $28)=8.41, M S_{\mathrm{e}}=0.023$, and higher for names that were old (hits) than those that were new (false alarms), $F(1,28)=$ 155.50, $M S_{\mathrm{c}}=0.016$. The interaction between attention condition and hits versus false alarms was also significant, $F(1,28)=42.79, M S_{\mathrm{e}}=0.016$. The probability of a hit was much higher and the probability of a false alarm was much lower in the full-attention (.63 and .00) than in the dividedattention (.30 and .11$)$ condition.

The results closely conformed to our expectations. The good list recognition of old nonfamous names in the fullattention condition allowed those names to be less likely to be called "famous" and more quickly rejected than were new nonfamous names. In contrast, dividing attention radically reduced list recognition. The failure to recognize old nonfamous names in combination with a gain in their familiarity is revealed by the finding that old nonfamous names were more likely to be called "famous" than were new nonfamous names in the divided-attention condition.

The results of these analyses lead us to conclude that gains in familiarity can be unaccompanied by list recognition. Given that old nonfamous names were more likely to be mistakenly called "famous" than were new nonfamous names, some of the old names must have gained familiarity without being recognized in the divided-attention condition. We also examined the stronger claim that divided attention, in comparison with full attention, while reading names had no effect on gains in familiarity. Because any recognized names (either hits or false alarms) would be called "nonfamous," the effects of familiarity gains can occur only for nonrecognized names. We used group data to estimate the probability of calling nonrecognized names "famous" separately for each of the two attention conditions. First, we used the recognition memory data to estimate the number of nonrecognized old and new nonfamous names on the fame test. That involved subtracting the estimated number of recognized names (based on the probability of calling a name "old") from 30 (the number of old and the number of new nonfamous names on the fame judgment test). Then we computed the probability of calling a nonrecognized name "famous" by dividing the number of names called "famous" by our estimated number of nonrecognized names for each combination of conditions (see Table 3).

Table 3

Probability of Judging a Nonrecognized Name Famous

\begin{tabular}{cccc} 
& & \multicolumn{2}{c}{$\begin{array}{c}\text { Nonfamous } \\
\text { name }\end{array}$} \\
\cline { 3 - 4 } Condition & Famous name: & New & Old \\
\hline Full attention & .62 & .31 & .51 \\
Divided attention & .49 & .19 & .39 \\
\hline
\end{tabular}

These data are consistent with the claim that the manipulation of attention had no effect on gains in familiarity produced by reading a name. The only effect of attention evident in those data is that subjects in the divided-attention condition were less willing to call any name "famous" than were subjects in the full-attention condition. This is simply the effect of divided attention on the criterion (discussed earlier) that subjects used for fame judgments. For nonrecognized names, old nonfamous names were more likely to be mistakenly called "famous" than were new nonfamous names, presumably because of the greater familiarity of old nonfamous names. This difference between old and new nonfamous names was identical in the two attention conditions.

To make our comparison of "corrected" fame judgments legitimate, it is not necessary to assume that list-recognition performance provides an accurate estimate of the absolute probability of list recognition when one is making fame judgments. Rather, it is necessary only that any source of error in that estimate not be different for the two attention conditions. The absolute probability of list recognition when one is making fame judgments probably did differ from that on the test of recognition memory. The delay between previously reading a name and the test of recognition memory was longer than that delay for the test of fame judgments. Also, the probability of recognizing an item on a direct test of list recognition is likely to be higher than the probability of using list recognition to monitor performance on a task such as fame judgments (Jacoby, Kelley, Brown, \& Jasechko, 1989). However, there is no reason to think that the effects of these factors differed for the two attention conditions.

Subjects in the full-attention condition could use list recognition to avoid being misled by the familiarity of old nonfamous names. Such a use of conscious recollection may be a generally important function. The influence of divided attention on the probability of judging an old nonfamous name as famous is similar to the "sleeper effect" observed in studies of social psychology (e.g., Cook, Gruder, Hennigan, \& Flay, 1979; Hovland, Lumsdaine, \& Sheffield, 1949). In those experiments, a message from a low-reliability source had little impact on attitudes measured immediately after the communication, but it did influence attitudes measured after a delay. Hovland et al. suggested that on the immediate test, the content of the message was discounted because its lowreliability source was readily accessible. However, discounting became less likely after a delay because the source of the message was forgotten. In a manner analogous to the impact of the delay in the sleeper effect, dividing attention while one is reading names made it less likely that conscious recollection of source (list recognition) could be used to reject old nonfamous names and resulted in those names' being more likely than new nonfamous names to be called famous. In other experiments, Jacoby, Kelley, Brown, and Jasechko (1989) showed that lengthening the retention interval between reading a name and its test can produce effects on fame judgments that are similar to those produced by dividing attention.

\section{Experiment 3}

Whereas attention in the first two experiments was divided during study, we investigated the effects of dividing attention 
during the fame-judgment test in Experiment 3 . We predicted that dividing attention during the test would prevent conscious recollection and produce effects that are similar to those produced by the dividing of attention during study. Whereas the dividing of attention during study prevents processing that is important for later conscious recollection, the dividing of attention during the test might limit a person's ability to make use of his or her memory for that processing in an act of recognition. In our example of trying not to repeat oneself, monitoring the past to avoid repetition is an attention-demanding act that might be impossible under conditions of divided attention.

\section{Method}

Subjects and design. The design was the same as that in Experiment 2, except that the manipulation of attention was during the fame test rather than during the original reading of nonfamous names. Judging fame while doing the listening task was quite difficult, tempting subjects to neglect the listening task. Consequently, performance on the listening task was used as a criterion for using subjects' data in the divided-attention condition. For subjects' data to be included, they could not miss more than $25 \%$ of the targets presented in the listening task. This rather stringent criterion ensured that subjects were dividing attention between the two tasks. Eleven subjects were not included in the study for failure to meet the criterion. The remaining subjects were 32 undergraduates enrolled in an introductory psychology course; there were 16 subjects in each of the two attention (full vs. divided) conditions. Names on the fame-judgment test were either famous, nonfamous and earlier read (old nonfamous), or nonfamous and not earlier read (new nonfamous).

Materials and procedure. The materials and procedure were the same as in Experiment 2, except for the change in when the attention manipulation occurred. During the fame-judgment test, subjects in the full-attention condition only made fame judgments, whereas those in the divided-attention condition simultaneously engaged in the task of listening for a series of three odd-numbered digits. Five famous and five nonfamous names were added as fillers to the beginning of the test lists used in Experiment 2. These additional names were presented for fame judgments to subjects in both attention conditions but were added to allow subjects in the divided-attention condition to settle into the listening task before presentation of the main test list. Presentation of names for fame judgments was controlled by the computer. One second after a fame judgment, the next name to be judged was presented. For the listening task, subjects responded verbally, saying "Now" when they detected a target sequence of three odd digits. If during the test phase subjects completed one full cycle through the list of 224 numbers used in the listening task, the list was repeated without interruption. Recognition memory was not tested.

\section{Results and discussion}

Subjects in the divided-attention condition missed an average of 6.5 of 52 targets in the listening task.

In a first analysis of the probability of calling a name "famous" (see Table 4) for each combination of conditions, we compared performance on famous and new nonfamous names to test for differences between the two attention conditions in accuracy of discrimination or in the criterion used for fame judgments. Famous names were more likely to be called "famous" than were new nonfamous names, $F(1,30)$ $=163.92, M S_{\mathrm{e}}=0.012$. Although subjects in the full-attention condition were slightly more willing to call a name "famous"
Table 4

Probability of Judging a Name Famous

\begin{tabular}{cccc}
\hline & & \multicolumn{2}{c}{$\begin{array}{c}\text { Nonfamous } \\
\text { name }\end{array}$} \\
\cline { 3 - 4 } Condition & $\begin{array}{c}\text { Famous name: } \\
\text { New }\end{array}$ & New & Old \\
\hline Full attention & .54 & .18 & .13 \\
Divided attention & .49 & .14 & .28 \\
\hline
\end{tabular}

than were subjects in the divided-attention condition, neither the main effect of attention condition nor the interaction of attention with fame was significant. A signal-detection analysis indicated no significant effects of attention condition on either the criterion used for judging a name famous or the accuracy of discrimination between famous and new nonfamous names.

Our central interest was in differences between the two attention conditions in performance on new nonfamous and old nonfamous names. An analysis of those probabilities showed that old nonfamous names were more likely to be called "famous" than were new nonfamous names, $F(1,30)$ $=6.20, M S_{\mathrm{e}}=0.005$. More important, the interaction between previously reading a name and attention condition was significant, $F(1,30)=28.52, M S_{e}=0.005$. As predicted, old nonfamous names were more likely to be called "famous" than were new nonfamous names in the divided-attention condition, whereas the opposite was true in the full-attention condition. This pattern of results is consistent with the interpretation that subjects in the full-attention condition used list recognition of names as a basis for rejecting old nonfamous names. Subjects whose attention was divided were left without sufficient resources to perform this list-recognition memory check.

Judgment times were consistent with this conclusion. An analysis of times to correctly reject nonfamous names showed a main effect of prior presentation of the name, $F(1,30)=$ 11.43 , as well as a significant interaction between prior presentation and attention condition, $F(1,30)=4.89, M S_{\mathrm{c}}=$ 31,389 . Old nonfamous names were rejected more rapidly than were new nonfamous names in the full-attention condition $(1,278$ vs. $1,526 \mathrm{~ms})$, whereas there was no difference in the times to reject old and new nonfamous names in the divided-attention condition (1,534 vs. $1,582 \mathrm{~ms}$ ). List recognition served as a basis for quickly rejecting old nonfamous names in the full-attention condition but could be used less often in the divided-attention condition. The two conditions did not differ in time taken to correctly call a famous name "famous" $(F<1)$.

We also examined the possibility that divided attention during the test had no effect on access to gains in familiarity as measured by fame judgments. Recognition data were not collected in this experiment. However, we used recognition data from Experiment 2 to estimate the probability of calling nonrecognized names famous in the full-attention condition. The use of list-recognition performance from one experiment in order to "correct" fame judgments in another experiment is more conservative than is using data for both types of judgment from the same experiment. To examine any differential effects of attention at test in responding to nonrecog- 
nized names, we made the strong assumption that dividing attention completely eliminated list recognition. Under that conservative assumption, it was unnecessary to correct fame judgments for list recognition in the divided-attention condition. According to these computations, the difference between the probabilities of mistakenly responding "famous" to old and new nonrecognized names in the full-attention condition (.35 vs. .18) was approximately the same as that in the dividedattention condition (.28 vs. .14). The small effect of attention condition that remained probably stemmed from the fact that dividing attention does not completely eliminate list recognition. Therefore, some proportion of items in the dividedattention condition were not susceptible to the false fame effect because they were recognized and quickly rejected as nonfamous. Regardless, one can conclude that divided attention, in comparison with full attention, when subjects were making fame judgments radically reduced the use of list recognition to reject nonfamous names but left in place the effects of prior presentation on the names' familiarity.

The effects of dividing attention while one is making fame judgments were almost identical to those of dividing attention during the initial presentation of nonfamous names. Recognition can suffer equally from a deficit in study or from a deficit in retrieval processing. For both study and retrieval, more demanding cognitive forms of processing that require attentional resources may be necessary for recognition (e.g., Craik, 1982; Jacoby, 1982; Warrington \& Weiskrantz, 1982).

The separability of the tool versus object functions of memory is seen when conscious recollection is used to monitor unconscious effects of the past. There may be large individual differences in the extent to which people monitor the past as a source of influence. The effects that we observed in the divided-attention condition may reflect individual differences in such monitoring. It was necessary to reject more than a third of the subjects tested in the divided-attention condition on the grounds of poor performance on the listening task. Subjects who did poorly on the listening task produced a pattern of results similar to that produced by subjects in the full-attention condition. Perhaps subjects who were unable to do the listening task while making fame judgments could not stop monitoring the past. In this regard, one of the authors (Jacoby) found it impossible to perform the listening task while judging fame and claimed to be unable to stop attempting to recognize the names. Those who were able to perform the listening task adequately while making fame judgments claimed that a "laid-back," largely uncritical approach to the fame judgment task was necessary.

\section{General Discussion}

We were successful in making names famous without their being recognized. By doing so, we extended results of earlier experiments (Eich, 1984; Koriat \& Feuerstein, 1976) that have shown differential effects of attention on conscious recollection, in comparison with other uses of memory. Dividing attention influenced people's ability to consciously recollect having read a name, as measured by list recognition, but left in place effects of reading a name on its familiarity, as indexed by fame judgments. Familiarity has been proposed as one of two processes in models of retrieval (e.g., Atkinson
\& Juola, 1974; Glucksberg \& McCloskey, 1981; Jacoby \& Brooks, 1984; Mandler, 1980). Assessing familiarity is said to often be a rapid process that enables subjects to respond quickly, whereas a second, often slower retrieval process generates further information before specifying a response. The results of our experiments provide strong evidence of the existence of these multiple bases for judgments. The differential effects of dividing attention on fame judgments and on list-recognition memory judgments provide one source of such evidence.

Our strategy of placing conscious recollection in opposition to effects on familiarity provides more conclusive evidence that conscious recollection and assessing familiarity serve as alternative bases for judgments. Effects on familiarity are an unconscious influence of memory in that they do not depend on conscious recollection. We can be certain that this is the case because in our later experiments, conscious recollection would produce a judgment that was opposite to that produced by gains in familiarity. In contrast to the conclusions that can be drawn from our experiments, Gillund and Shiffrin (1984) used different procedures and concluded that they were unable to find any convincing evidence of multiple bases for recognition memory decisions. Our strategy of placing different bases for judgments in opposition allows their clear separation.

\section{A Processing Account of Unconscious Influences}

In other studies of the relation between attention and memory, researchers found that when attention to items was eliminated during study, later recognition performance was near chance (e.g., Fisk \& Schneider, 1984). Rather than attempting to fully eliminate attention, we ensured some processing of names in our experiments by requiring subjects to read the names aloud in both divided- and full-attention conditions. Under those circumstances, the pattern of results produced by the dividing of attention during study was similar to that observed for amnesics by Huppert and Piercy (1978). Mandler (1980) interpreted results of this sort as showing that amnesics preserve the ability to assess familiarity without the capability of conscious recollection or memory for study context. This deficit has been said to result from amnesics' inability to form a memory representation of study context (e.g., Hirst, 1982). Similarly, divided attention during study can be described as producing a failure to store study context (Craik, 1982). The results of our experiments would then be interpreted as showing that divided attention did not influence memory for content (memory for the names as shown by fame judgments) but did influence memory for context (as shown by list-recognition memory judgments).

However, the conclusion that the dividing of attention prevented subjects from encoding context must be treated with caution. A test of list recognition is a direct test of memory in that people are instructed to base their decisions on their ability to report study context. Performance on indirect memory tests can reveal effects of reinstating context even when context cannot be reported (Kelley, Jacoby, \& Hollingshead, in press). When attention was divided during study, context may have been represented in some form that would support performance on an indirect test but not on a 
direct test of memory. Also, an account in terms of an inability to store context ignores the parallel results produced by the dividing of attention during the test and the dividing of attention during study. We prefer to describe the effects of dividing attention in terms of differences in processing so as to emphasize that parallel and to emphasize other relations among effects on different types of task.

By emphasizing differences in processing, one can reveal relations among tasks that would be ignored if one described effects as produced by a failure to $a d d$ a representation of study context to that of the content of studied material. In this vein, Dywan and Jacoby (1988) showed that people's susceptibility to familiarity errors is correlated with performance on other tasks. Dywan and Jacoby used the famejudgment task to investigate differences among the aged in their memory performance. As in the later experiments reported here, Dywan and Jacoby placed effects on familiarity in opposition to conscious recollection by presenting only nonfamous names to be read. The difference between the probability of calling an old nonfamous name "famous" and that of calling a new nonfamous name "famous" served as a measure of the likelihood of a familiarity error for each subject and was correlated with the subject's performance on other tasks. Dywan and Jacoby found that subjects who were likely to make a familiarity error were also more likely to make errors when copying a complex figure and were less likely to cluster words by category when recalling a categorized list than were subjects who were unlikely to make a familiarity error. The processing disrupted by divided attention could also be involved in monitoring of the sort necessary to note relations among items in a categorized list and to avoid copying errors. The correlation between familiarity errors and clustering calls into question the claim that memory for context is fully separate from memory for content. Indeed, there are other data to show that memory for temporal relations (an aspect of memory for context) depends on noting relations among items in a list, the same activity required for clustering. Winograd and Soloway (1985) found better recency judgments for related pairs than for unrelated pairs of words. They argued that subjects are reminded of the earlier item when they encounter the second related item and that reminding establishes a relation that supports recency judgments.

Craik (e.g., 1982) used the term elaboration to refer to the type of processing that is influenced by the dividing of attention and is important for remembering the context in which an event occurred. We agree with Craik in many ways, but we hesitate to adopt the term elaboration. Elaboration usually refers to differences in the processing of meaning, and we do not believe that the effects of dividing attention that we observed were produced by such differences. It is not clear that nonfamous names have any meaning, and in any case, subjects were required only to pronounce the names, a task that does not encourage the processing of meaning. One could consider famous names to be more meaningful to subjects than nonfamous names. If it is the processing of the meaning of individual items that is influenced by the dividing of attention and is responsible for effects on list recognition, one would expect an interaction between manipulations of attention and the meaningfulness of those items. The list of names read in our first experiment did include famous, as well as nonfamous, names. List-recognition performance in that experiment showed a main effect of divided attention and a main effect of famous versus nonfamous names (meaningfulness of names) but did not reveal a significant interaction between those two factors. In this vein, interactions between manipulations of the processing of meaning and state differences, such as intoxication, that are thought to reflect differences in attention are also often not found (Hartley, Birnbaum, \& Parker, 1978). We think the processing influenced by divided attention is better described as reflection (Johnson, 1983) or as treating memory as an object (Jacoby \& Kelly, 1987). One possibility is that treating an experience as an object is necessary to define that experience as a separate event and is also necessary for conscious recollection and comparison of that event with other events.

In contrast to our results, divided attention does not always simulate the effects of amnesia. Nissen and Bullemer (1987) found that both normal subjects and amnesics improved with practice on a serial reaction time task that comprised a repeating 10-trial sequence. Unlike the normal subjects, the amnesics were not aware of the repeating sequence. Divided attention during training was meant to produce results for normal subjects that paralleled those of amnesics: learning in the absence of ability to report the repeating sequence. However, divided attention disrupted the learning of normal subjects, as well as their ability to become aware of the repeating patterns. We speculate that the secondary task used by Nissen and Bullemer had its effects on learning by disrupting the continuity of the repeating sequence of trials in the serial reaction time task, thereby producing a change in segmentation. The structure of a task, as well as the ability to verbalize relations, can probably be affected by the dividing of attention. To anticipate the effects of divided attention on memory, it is probably necessary to more fully specify the relation between the secondary task used to divide attention and the requirements of the criterial task (Broadbent, 1989; Neisser, 1980).

\section{Conscious Recollection as a Separate Act}

The rationale underlying our experiments was that conscious recollection often serves to oppose unconscious influences of memory. When unopposed by conscious recollection, reading a name that one is told is nonfamous increases the probability that that name will later be called "famous." Conscious recollection is required to discriminate the familiarity produced by having recently read a name from the familiarity produced by the name's being a famous one. As well as making nonfamous names seem famous, unconscious influences of the past can serve to increase the accuracy of perception (e.g., Jacoby \& Dallas, 1981), reduce the subjective loudness of a background noise (Jacoby, Allan, Collins, \& Larwill, 1988), and reduce the judged difficulty of anagrams (Jacoby \& Kelley, 1987). Jacoby and Kelley (1987) and Jacoby, Kelley, and Dywan (1989) found it useful to think about these unconscious influences of the past versus conscious recollection in terms of Polanyi's (1958) distinction between tool and object. According to the tool/object distinction, familiarity and other unconscious influences of the past 
stem from the use of memory as a tool to perceive and interpret later events. When used as a tool, memory for a prior event is incorporated into an ongoing activity rather than treated as an object of reflection. Specifying the source of familiarity requires a change in the focus of attention from the task at hand to reflecting on the past; that is, conscious recollection requires an act that is separate from the use of memory as a tool and serves to attribute effects of the past to their source. Even when it is possible to specify the source, people may fail to do so spontaneously.

In this regard, perhaps the most interesting finding from our experiments is that dividing attention during the test produced essentially the same results as did dividing attention while subjects earlier read nonfamous names. Dividing attention at the time of test reduced the likelihood of conscious recollection while leaving in place the effects of earlier reading a name on its familiarity, which made it likely that old nonfamous names would mistakenly be called "famous." This finding is consistent with the claim that conscious recollection is an attention-demanding act that is separate from other uses of memory. Recognition of an item as previously presented is not always automatic or spontaneous even when that item gives rise to a feeling of familiarity.

Questions about automaticity have most often centered on whether the encoding of some type of information is automatic (e.g., Hasher \& Zacks, 1979). Treating recollection as a separate act encourages the use of manipulations such as the dividing of attention both at the time of test and during study. In contrast to our results, Baddeley, Lewis, Eldridge, and Thomson (1984) observed very small effects of varying attention at test and concluded that retrieval from memory is largely automatic. A potentially important difference between their experiments and ours is that they instructed their subjects to recall or recognize items. In our experiments, list recognition was not a primary objective for subjects but, rather, served as a means of avoiding being misled by familiarity when judging fame. That is a difference between spontaneous and directed recognition. Perhaps gaining the orientation toward conscious recollection (treating memory as an object), rather than the act of retrieval itself, is what demands attention.

In most investigations of conscious recollection, researchers have relied on directly asking people to report on the past or to recognize an item as previously presented. Those procedures might lead to an overestimate of the probability of "spontaneous" recollection. Fame judgments provided us with a measure of spontaneous recollection. Subjects were not directly asked to consciously recollect names as previously read, but recollection of the source of a name's familiarity would produce a fame judgment that was opposite to that produced by a failure to recollect the source. That arrangement allows one to use effects on fame judgments to infer whether recollection of earlier reading a name was spontaneous-recollected when people were not directly asked to do so. In that light, our results show that spontaneous recollection is less likely when attention is divided at the time of test.

People may neglect to spontaneously recollect even when they have the attentional capacity to do so if directed. Jacoby, Kelley, Brown, and Jasechko (1989) showed that people make errors in fame judgments that could be avoided if they were directly asked to consciously recollect earlier reading a name (make list-recognition judgments), as well as making fame judgments. In other words, errors that reflect a failure to monitor unconscious influences of the past can arise because of people's failure to spontaneously attempt conscious recollection even when they could consciously recollect the relevant experience in response to a direct question. The most common cause of unconscious influences may be a failure to spontaneously note or realize the significance of some earlier event rather than an inability to do so when directly asked (Bowers, 1984). By focusing on the test as the locus for manipulations, we have an opportunity to learn more about the situations that encourage self-monitoring (e.g., Snyder, 1974), as well as about types of monitoring that are important to avoid unconscious influences of the past.

Counter to folk wisdom, conscious recollection can serve as a means of avoiding misleading effects of the past rather than being a prerequisite for effects of the past. Placing conscious recollection in opposition to misleading effects of the past has the advantage of clearly separating conscious from unconscious influences of memory. Our results suggest that the retrieval orientation required for monitoring the past as a potential source of effects on performance is functionally independent from other uses of memory. Dividing attention at test selectively interfered with the use of list recognition to reject old nenfamous names. Manipulations at test provide an additional means of exploring the relation between different functions of memory.

\section{References}

Atkinson, R. C., \& Juola, J. F. (1974). Search and decision processes in recognition memory. In D. H. Krantz, R. C. Atkinson, R. D. Luce, \& P. Suppes (Eds.), Contemporary developments in mathematical psychology: Vol. 1. Learning, memory and thinking (pp. 243-293). San Francisco: Freeman.

Baddeley, A., Lewis, V., Eldridge, M., \& Thomson, N. (1984). Attention and retrieval from long-term memory. Journal of Experimental Psychology: Generat. 113, 518-540.

Bowers, K. S. (1984). On being unconsciously influenced and informed. In K. S. Bowers \& D. Meichenbaum (Eds.), The unconscious reconsidered (pp. 227-273). New York: Wiley.

Broadbent, D. E. (1989). Lasting representations and temporary processes, In H. L. Roediger \& F. 1. M. Craik (Eds.), Varieties of memory and consciousness: Essays in honor of Endel Tulving. Hillsdale, NJ: Erlbaum.

Cook, T. D., Gruder, C. L., Hennigan, K. M., \& Flay, B. R. (1979). History of the sleeper effect: Some logical pitfalls in accepting the null hypothesis. Psychological Bulletin, 86, 662-679.

Craik, F. I. M. (1982). Selective changes in encoding as a function of reduced processing capacity. In F. Klix, J. Hoffman, \& E. van der Meer (Eds.), Cognitive research in psychology (pp. 152-161). Berlin: Deutscher Verlag der Wissenschaffen.

Dywan, J., \& Jacoby L. L. (1988). Effects of aging on source monitoring: Differences in susceptibility to false fame. Manuscript submitted for publication.

Eich, E. (1984). Memory for unattended events: Remembering with and without awareness. Memory \& Cognition, 12, 105-111.

Fisk, A. D., \& Schneider, W. (1984). Memory as a function of attention, level of processing, and automatization. Journal of Experimental Psychology: Learning. Memory, and Cognition, 10, 181-197.

Gillund, G., \& Shiffrin, R. M. (1984). A retrieval model for both 
recognition and recall. Psychological Review, 91, 1-67.

Glucksberg, S., \& McCloskey, M. (1981). Decisions about ignorance: Knowing that you don't know. Journal of Experimental Psychology: Human Learning and Memory, 7, 311-325.

Grand, S., \& Segal, S. J. (1966). Recovery in the absence of recall: An investigation of color-word interference. Journal of Experimental Psychology, 72, 138-144.

Hartley, J. T., Birnbaum, I. M., \& Parker, E. S. (1978). Alcohol and storage deficits: Kind of processing? Journal of Verbal Learning and Verbal Behavior, 5, 635-647.

Hasher, L., \& Zacks, R. T. (1979). Automatic and effortful processes in memory. Joumal of Experimental Psychology: General, 108, 356-388.

Hirst, W. (1982). The amnesic syndrome: Descriptions and explanations. Psychological Bulletin, 91, 435-460.

Hovland, C. I., Lumsdaine, A. A., \& Sheffield, F. D. (1949). Experiments on mass communication. Princeton, NJ: Princeton University Press.

Huppert, F. A., \& Piercy, M. (1978). The role of trace strength in recency and frequency judgments by amnesic and control subjects. Quarterly Journal of Experimental Psychology, 30, 346-354.

Jacoby, L. L. (1982). Knowing and remembering: Some parallels in the behavior of Korsakoff patients and normals. In L. S. Cermak (Ed.), Human memory and amnesia (pp. 97-122). Hillsdale, NJ: Erlbaum.

Jacoby, L. L., Allan, L. G., Collins, J. C., \& Larwill, L. K. (1988). Memory influences subjective experience: Noise judgments. Journal of Experimental Psychology: Learning. Memory, and Cognition, 14, 240-247.

Jacoby, L. L., \& Brooks, L. R. (1984). Nonanalytic cognition: Memory, perception and concept learning. In G. H. Bower (Ed.), The psychology of learning and motivation: Advances in research and theory, Vol. 18 (pp. 1-47). New York: Academic Press.

Jacoby, L. L., \& Dallas, M. (1981). On the relationship between autobiographical memory and perceptual learning. Journal of EXperimental Psychology: General, 110, 306-340.

Jacoby, L. L., \& Kelley, C. M. (1987). Unconscious influences of memory for a prior event. Personality and Social Psychology Bulletin, 13, 314-336.

Jacoby, L. L., Kelley, C. M., Brown, J., \& Jasechko, J. (1989). Becoming famous overnight: Limits on the ability to avoid unconscious influences of the past. Journal of Personality and Social Psychology, 56. 326-338.

Jacoby, L. L., Kelley, C. M., \& Dywan, J. (1989). Memory attributions. In H. L. Roediger \& F. I. M. Craik (Eds.), Varieties of memory and consciousness: Essays in honor of Endel Tulving (391422). Hillsdale, NJ: Erlbaum.

Johnson, M. K. (1983). A modular model of memory. In G. H. Bower (Ed.), The psychology of learning and motivation: Advances in research and theory, Vol. 17 (pp. 81-123). New York: Academic Press.

Kelley, C. M., Jacoby, L. L., \& Hollingshead, A. (in press). Direct versus indirect tests of memory for source: Judgments of modality. Journal of Experimental Psychology: Learning, Memory, and Cognition.

Koriat, A., \& Feuerstein, N. (1976). The recovery of incidentally acquired information. Acta Psychologica, 40, 463-474.

Mandler, G. (1980). Recognizing: The judgment of previous occurrence. Psychological Review, 87, 252-271.

Moray, N. (1959). Attention in dichotic listening: Affective cues and the influence of instructions. Quarterly Journal of Experimental Psychology, 11, 56-60.

Morton, J. (1969). Interaction of information in word recognition. Psychological Review, 76, 165-178.

Neely, J. H., \& Payne, D. G. (1983). A direct comparison of recognition failure rates for recallable names in episodic and semantic memory tests. Memory \& Cognition, 11, 161-171.

Veisser, U. (1980). The limits of cognition. In P. Jusczyk \& R. Klein (Eds.), The nature of thought: Essays in honor of D. O. Ilebb (pp. 115-132). Hillsdale, NJ: Erlbaum.

Nissen, M. J., \& Bullemer, P. (1987). Attentional requirements of learning: Evidence from performance measures. Cognitive $P_{s y-}$ chology, 19, 1-32.

Polanyi, M. (1958). Personal knowledge: Towards a post-critical philosophy. Chicago: University of Chicago Press.

Richardson-Klavehn, A., \& Bjork, R. A. (1988). Measures of memory. Annual Review of Psychology, 39, 475-543.

Snyder, M. (1974). The self-monitoring of expressive behavior. Journal of Personality and Social Psychology, 30, 526-537.

Warrington, E. K., \& Weiskrantz, L. (1982). Amnesia: A disconnection syndrome? Neuropsychologia, 20, 233-248.

Winograd, E., \& Soloway, R. M. (1985). Reminding as a basis for temporal judgments. Journal of Experimental Psychology: Learn. ing, Memory, and Cognition, 11, 262-271.

Received March 9, 1988

Revision received September 23, 1988 Accepted September 29, 1988

\section{Hunt Appointed Editor of JEP: General, 1990-1995}

The Publications and Communications Board of the American Psychological Association announces the appointment of Earl B. Hunt, University of Washington, as editor of the Journal of Experimental Psychology: General for a 6-year term beginning in 1990. As of January 1, 1989, manuscripts should be directed to

Earl B. Hunt

Department of Psychology NI-25

University of Washington

Seattle, Washington 98195 